\title{
Outcome of Early Surgical Intervention in Acute Lower Limb Ischemia due to Thromboembolism
}

\author{
QA Azad ${ }^{1}$, NAK Ahsan ${ }^{1}$, AM Asif Rahim¹, SAN Alam ${ }^{1}$, M Rahman $^{2}$ \\ ${ }^{1}$ Department of Cardiovascular Surgery, NICVD, Dhaka, and \\ ${ }^{2}$ Department of Vascular Surgery, BSMMU, Dhaka
}

Keywords:

Acute limb

ischaemia,

Thromboembolism.

\begin{abstract}
:
Background: Acute lower extremity ischemia is a common vascular disease and considered limb-and life- threatening. The present study evaluated and compared the outcome of early and late surgical intervention in acute lower limb ischemia due to thromboembolism.

Methodology: This non randomized comparative parallel study was conducted at the Department of Cardiovascular Surgery, NICVD, Dhaka, Bangladesh from January 2007 to December 2008 for duration of two year. Total 80 patients were enrolled in this study. The patients were divided into equal two groups, Group A, for early surgical intervention (with in 24 hours) and Group B, late surgical intervention (more than 24 hours).

Results: Mean $( \pm S D)$ age of both Group A and Group B was 51.93 ( \pm 11.73$)$ and 47.00 ( \pm 11.01$)$ years. Male and female ratio of the total study population was 1.76:1 Pain and absence of pulse distal to occlusion was common for all. Cold extremity, sensory deficit, motor deficit, diminish vascular flow was the commonest findings of both group. In Group A, 57.5\% had superficial femoral artery occlusion, $22.5 \%$ had iliac artery and $20.0 \%$ popliteal artery occlusion. In Group B, 42.5\% had superficial femoral artery occlusion, $32.5 \%$ had popliteal artery occlusion and $25.0 \%$ had iliac artery occlusion. Fasciotomy was performed in 15.0\% patients of Group A and in $22.0 \%$ patients of Group B. After Fogarty embolectomy in group A and group B had warm extremity (80.0\% vs. $65.0 \%)$, pulsation distal to occlusion (90.0\% vs. $75.0 \%)$, intact sensory function (82.5\% vs. $67.5 \%$ ), intact motor function (80.0\% vs. $65.0 \%$ ), and normal vascular flow by Doppler US (80.0\% vs. $65.0 \%)$. During postoperative period history of bleeding, infection, reperfusion injury, muscle necrosis and limb amputation were $12.5 \%$ vs. $10.0 \%, 5.0 \%$ and $7.5 \%, 17.5 \%$ vs. $35.0 \%, 15.0 \%$ vs. $12.5 \%$ and $37.5 \%$ vs. $32.5 \%$ respectively.

Conclusion: Duration of embolism may be the significant factor determining the outcomes of the management of acute arterial embolism in the lower extremities. The 24- hour duration of arterial embolism is a crucial factor influencing the surgical the management and early diagnosis and shifting of patients to specified centre as early as possible to save limb as well as life.
\end{abstract}

(Cardiovasc. j. 2014; 7(1): 38-43)

\section{Introduction:}

Acute lower extremity ischemia (ALI) is a common vascular disease and is a cause of considerable morbidity and mortality. It is considered as limb-and life-threatening condition usually requiring revascularization therapy within 24 hours. ${ }^{1}$ Acute peripheral arterial occlusion (APAO) can be associated with a spectrum of presenting signs and symptoms. In an extreme case, a patient without underlying arterial occlusive disease who suffers from an acute embolic occlusion at the superficial femoral bifurcation may present with a profoundly ischemic lower extremity, requiring urgent intervention. ${ }^{2}$ It is well established that arterial embolism is a common cause of acute lower limb ischemia. Emboli from the proximal sources either cardiac or proximal aorta commonly occlude the bifurcation of the arteries of the lower extremity. ${ }^{3-6}$ Despite many progresses in the fields of the immediate management of ALI and in the area of the revascularization procedures, APAO continues to be associated with substantial limb loss and considerable mortality. Indeed, most recent large series report that 30 -day mortality still accounts for approximately $15.0 \%$, while the amputation rate $(10.0 \%-30.0 \%)$ varies much more. ${ }^{7}$ Embolectomy is generally indicated in the presence of severe acute ischemia, usually indicated by loss of sensitivity, discolouration of

Address of Correspondence: Dr Quazi Abul Azad, Department of Cardiovascular Surgery, National Institute of Cardiovascular Diseases, Dhaka, Bangladesh. E-mail: qaazad12@yahoo.com 
the skin, decreased skin temperature and moderate rigor of the muscles. Although early diagnosis and treatment is important, the time factor does not contraindicate the surgical treatment itself. When ischemia becomes irreversible, there is blotchy cyanotic discolouration not influenced by digital pressure, the calf muscle has a firm consistency and there is anesthesia and paralysis of the extremity. ${ }^{2}$ Very little published epidemiological data are available to establish the real incidence of APAO in the general population. An audit carried out in Gloucestershine have found a 14/100,000 incidence of acute limb ischemia (ALI) in the general population, which increases to 17 per 100,000 if bypass graft occlusions were included. ${ }^{8}$ The Swedish Vascular Registry confirms the data, reporting 13/100,000 regional incidence. ${ }^{9}$

A few study of management of peripheral limb ischemia were done previously in Bangladesh. They were limited on outcome of treatment of peripheral limb ischemia irrespective of the time of intervention. This comparative study evaluated the outcome of early surgical intervention in lower limb ischemia due to thromboembolism.

\section{Methods and Materials:}

The present study evaluated the outcome of early and late surgical intervention in acute lower limb ischemia due to thromboembolism. It was a non randomized comparative parallel study conducted in the Department of Cardiovascular Surgery, National Institute of Cardiovascular Diseases (NICVD), Dhaka, Bangladesh between the periods January 2007 and December 2008.

Patients who were scheduled for surgical revascularization for ALI due to thromboembolism were enrolled in the study. Convenient non-probability sampling technique was applied in the study. Total number of patients was 80 . The patients were divided into equal two groups. Group A $(n=40)$ for early surgical intervention (within 24 hours) and Group B $(\mathrm{n}=40)$ for late surgical intervention (more than 24 hours). Patient with chronic lower limb ischemia, patient with major tissue loss or permanent nerve damage, patient with prosthetic graft, patients with gangrenous limb, patients with known pre-existing peripheral vascular disease and re-operation were excluded from the study. Doppler studies were done in every patient before and after operation for diagnosis and to evaluate post operative out come. All data were analyzed by using computer based SPSS (statistical programme for social science). Data were expressed in frequency, percentage, mean \pm SD as applicable. Comparison between the groups was done by Chi-squared test and Student t test as applicable. $\mathrm{p}$ value of less than 0.05 was considered as significant.

\section{Results:}

In the present study Mean $( \pm \mathrm{SD})$ age of Group A and Group B were 51.93 ( \pm 11.73) and 47.00 ( \pm 11.01) years respectively. In Group A maximum $30.0 \%$ belonged to 45 to 55 years age range followed by $25.0 \%$ within $55-65$ years, $20.0 \%$ were within 35 to 45 years, $15 \%$ above 65 years and $10.0 \%$ up to 35 years age range. In Group B maximum $42.5 \%$ belonged to 35 to 45 years age group followed by $32.5 \%$ within 45 to 55 years, $10.0 \%$ above 65 years, $7.5 \%$ up to 35 years and $7.5 \%$ 55-65 years age group. Male and female in Group A and in Group B were 67.5\% and 32.5\% and $60.0 \%$ and $40.0 \%$ respectively.

Regarding occupation in Group A, service holder, housewife, businessman, retired and other professionals were $12.5 \%, 32.5 \%, 30.0 \%, 15.0 \%$, and $10.0 \%$ respectively and in Group B they were $25.0 \%$ maximum $37.5 \%, 7.5 \% 10.0 \%$ and $20.0 \%$ respectively. Smoker in Group A and Group B were $62.5 \%$ and $50.0 \%$ respectively. In Group A and Group B there were $42.5 \%$ and $27.5 \%$ had diabetes mellitus respectively. In group A 55.0\% were hypertensive and in group B 40.0\% were hypertensive (Table I). All patients of group A and group B had history of pain and absence of pulse distal to occlusion. $92.5 \%$ patients of group A had cold and $7.5 \%$ had warm extremity, on the other side in group B $97.5 \%$ had cold and $2.5 \%$ had warm extremity. Intact sensory function in Group A and Group B were 12.5\% and $7.5 \%$ respectively and intact motor function were $20.0 \%$ and $10.0 \%$ respectively.

By Doppler USG evaluation only $2.5 \%$ patients of Group A had found diminish vascular flow and rests $97.5 \%$ had absent vascular flow, in Group 
B 5.0\% and $95.0 \%$ patients had diminished and absent vascular flow respectively (Table II). In Group A maximum had occlusion in superficial femoral artery (57.5\%) followed by iliac artery $(22.5 \%)$ and popliteal artery (20.0\%). In Group B occlusion in superficial femoral artery, popliteal artery and iliac artery occlusion were $42.5 \%$, $32.5 \%$ and $25.0 \%$ respectively. In patients of Group A 27.5\% had viable muscle, $67.5 \%$ had borderline and 5.0\% had no viability. In Group B $22.5 \%$ had viable muscle, $67.5 \%$ had borderline and $10.0 \%$ had dead muscle.

Table-I

Distribution of characteristics of patients by group.

\begin{tabular}{|c|c|c|c|}
\hline & $\begin{array}{c}\text { Group A } \\
n=40\end{array}$ & $\begin{array}{c}\text { Group B } \\
n=40\end{array}$ & $\mathrm{p}$ value \\
\hline \multicolumn{4}{|l|}{ Age(yrs) } \\
\hline$<35$ & $04(10.0)$ & $03(07.5)$ & \\
\hline $35-45$ & $08(20.0)$ & $17(42.5)$ & \\
\hline $45-55$ & $12(30.0)$ & $13(32.5)$ & \\
\hline $55-65$ & $10(25)$ & $03(7.5)$ & \\
\hline$>65$ & 06(15) & $04(10.0)$ & \\
\hline Mean \pm SD & $51.93 \pm 11.73$ & $47.00 \pm 11.01$ & $0.056^{* * *}$ \\
\hline \multicolumn{4}{|l|}{ Sex } \\
\hline Male & $27(67.5)$ & $24(60.0)$ & \\
\hline Female & $13(32.5)$ & $16(40.0)$ & $0.485^{*}$ \\
\hline $\begin{array}{l}\text { Occupation } \\
\text { Service }\end{array}$ & $05(12.5)$ & $10(25.0)$ & \\
\hline Housewife & $13(32.5)$ & $15(37.5)$ & \\
\hline Business & $12(30.0)$ & $03(07.5)$ & 0.063 \\
\hline Retired & $06(15.0)$ & 04(10.00 & \\
\hline others & 04(10.0) & 08(20.0) & \\
\hline $\begin{array}{l}\text { Habits } \\
\text { Smoking }\end{array}$ & $25(62.5)$ & $20(50.0)$ & $0.260^{*}$ \\
\hline Alcohol & 03(07.5) & 03(0.75) & $0.999 *$ \\
\hline $\begin{array}{l}\text { Comorbid Disea } \\
\text { Diabetes } \\
\text { Mellitus }\end{array}$ & $\begin{array}{l}\text { ases } \\
\qquad 17(42.5)\end{array}$ & $11(27.5)$ & $0.160^{*}$ \\
\hline Hypertension & $22(55.0)$ & $16(40.0)$ & $0.179 *$ \\
\hline $\begin{array}{l}\text { Ischaemic } \\
\text { heart disease }\end{array}$ & $15(37.5)$ & $12(30.0)$ & $0.478^{*}$ \\
\hline Atrial fibrillation & $18(45.0)$ & $24(60.0)$ & $0.179 *$ \\
\hline Mitral stenosis & $06(15.0)$ & $03(07.5)$ & $0.479 * *$ \\
\hline Stroke & $02(05.0)$ & $02(05.5)$ & $0.999 * *$ \\
\hline
\end{tabular}

*Chi-square test was done to measure the level of significant

**With Yates's correction

$* * *$ t test was done to measure the level of significant
Table-II

Distribution of the clinical presentation and laboratory finding group.

\begin{tabular}{lccc}
\hline & $\begin{array}{c}\text { Group A } \\
(\mathrm{n}=40)\end{array}$ & $\begin{array}{c}\text { Group B } \\
(\mathrm{n}=40)\end{array}$ & P value \\
\hline Limb pain & $40(100.0)$ & $40(100.0)$ &
\end{tabular}

Limb Temp

$\begin{array}{llll}\text { Cold } & 37(92.5) & 39(97.5) & 0.608^{* *}\end{array}$

warm $\quad$ 03(07.5) 01(02.5)

Absence of pulse 40(100.0) 40(100.0)

beyond occlusion

Sensory function

Intact $\quad 05(12.5) \quad 03(07.5) \quad 0.709 * *$

Diminish 35(87.5) 37(92.5)

Motor function

$\begin{array}{llll}\text { Intact } & 08(20.0) & 04(10.0) & 0.210^{*} \\ \text { Diminished } & 32(80.0) & 36(90.0) & \end{array}$

Doppler finding beyond occlusion

Diminished $\quad 01(02.5) \quad 02(05.0)$

Absent 39(97.5) 38(95.0) $0.999 * *$

*Chi-square test was done to measure the level of significant **With Yates's correction

Fasciotomy was performed in $15.0 \%$ patients of group A and 22.0\% patients of Group B. After Fogarty embolectomy $80.0 \%$ patient of Group A and $65.0 \%$ of Group B had warm extremity, $90.0 \%$ and $75.0 \%$ patients of both Group A and Group B had pulsation distal to occlusion respectively. In Group A and Group B 82.5\% and $67.5 \%$ patients had intact sensory function and $80.0 \%$ and $65.0 \%$ had intact motor function. Doppler USG evaluates $80.0 \%$ patients of Group A and $65.0 \%$ patients of Group B had normal vascular flow. During postoperative period $12.5 \%$ patients of Group A and $10.0 \%$ of Group B had history of bleeding, $5.0 \%$ of Group A and $7.5 \%$ of Group B had developed infection, 17.5\% patients of Group A and $35.0 \%$ patients of Group B had reperfusion injury. Muscle necrosis and limb amputation was observed in $15.0 \%$ and $12.5 \%$ patients of Group A and $37.5 \%$ and $32.5 \%$ patients of Group B respectively (Table III). 
Table-III

Distribution of Site of arterial occlusion, per operative findings, outcome and complications by group.

\begin{tabular}{|c|c|c|c|}
\hline & $\begin{array}{c}\text { Group A } \\
n=40\end{array}$ & $\begin{array}{c}\text { Group B } \\
n=40\end{array}$ & $\mathrm{P}$ value* \\
\hline \multicolumn{4}{|l|}{ Site of occlusion } \\
\hline Iliac artery & $09(22.5)$ & $10(25.0)$ & \\
\hline SupFemoralartery & $23(57.5)$ & $17(42.5)$ & 0.342 \\
\hline Popliteal artery & $08(20.0)$ & $13(32.5)$ & \\
\hline \multicolumn{4}{|l|}{ Muscle Viability } \\
\hline Absent & $02(05.0)$ & $04(10.0)$ & \\
\hline Borderline & $27(67.5)$ & $27(67.5)$ & \\
\hline $\begin{array}{l}\text { Fasciotomy } \\
\text { performed }\end{array}$ & 06(15.0) & $09(22.5)$ & 0.390 \\
\hline $\begin{array}{l}\text { Outcomes } \\
\text { Diminished } \\
\text { Temperature } \\
\text { of Limb }\end{array}$ & $08(20.0)$ & $14(35.0)$ & 0.133 \\
\hline $\begin{array}{l}\text { Presence Pulse } \\
\text { beyond occlusion }\end{array}$ & $36(90.0)$ & $30(75.0)$ & 0.077 \\
\hline $\begin{array}{l}\text { Intact Sensory } \\
\text { function }\end{array}$ & $33(82.5)$ & $27(67.5)$ & 0.121 \\
\hline $\begin{array}{l}\text { Motor function } \\
\text { intact }\end{array}$ & $32(80.0)$ & $26(65.0)$ & 0.133 \\
\hline \multicolumn{4}{|c|}{ Doppler beyond occlusion } \\
\hline Normal & $32(80.0)$ & $26(65.0)$ & \\
\hline Diminish & $05(12.5)$ & $09(22.5)$ & 0.322 \\
\hline Absent & $03(07.5)$ & $05(12.5)$ & \\
\hline \multicolumn{4}{|l|}{ Complications } \\
\hline Bleeding & $05(12.5)$ & $04(10.0)$ & $0.999 * *$ \\
\hline Infection & 02(05.0) & 03(07.5) & $0.999 * *$ \\
\hline $\begin{array}{l}\text { Reperfusion } \\
\text { injury }\end{array}$ & $07(17.5)$ & $14(35.5)$ & $0.075^{* *}$ \\
\hline Muscle necrosis & $06(15.0)$ & $15(37.5)$ & $0.022^{* *}$ \\
\hline Limb amputation & $05(12.5)$ & $13(32.5)$ & $0.032 * *$ \\
\hline Death & $02(05)$ & $04(10.0)$ & $0.671^{* *}$ \\
\hline
\end{tabular}

*Chi-square test was done to measure the level of significant **With Yates's correction

\section{Discussion:}

Acute lower extremity ischemia continues to be associated with significant limb loss and mortality despite advances in endovascularbased therapies and overall improved critical care. ${ }^{1}$ In the present study total 80 patients with acute lower limb ischemia were enrolled and they were divided into equal two groups, Group A for early surgical intervention (within 24 hours) and Group B for late (more than 24 hours). The aim of this study was to evaluate the outcome of surgical intervention in acute lower limb ischemia due to thromboembolism. In the present study the mean $( \pm \mathrm{SD})$ of age in Group A and Group B were $51.93( \pm 11.73)$ and $47.00( \pm$ 11.01) years respectively. In the present study in Group A $67.5 \%$ were male and $32.5 \%$ were female and in Group B 60.0\% were male and $40.0 \%$ were female. Male and female ratio was 1.76:1. Antusevas and Aleksynas, ${ }^{10}$ in a study of 74 men with acute ischemia in the lower limb found that mean $\pm \mathrm{SD}$ of age was $68.3 \pm 12$ years, and for 68 women that was76.2 48 years. In Mutirangura et al. ${ }^{11}$ series mean $( \pm \mathrm{SD})$ age of early acute and late acute group was $61.0 \pm 17.0$ and $61.6 \pm 17.0$ years respectively which was inconsistent with our result. Iyem and Eren, ${ }^{12}$ in a study of the 122 patients showed that mean \pm SD of age was $54.2 \pm 16.8$ years. In their study 71 were male and 51 were female. In Mutiranrura et al. ${ }^{11}$ series in early acute group male and female was $48.4 \%$ and $51.6 \%$ and in late acute group $70.0 \%$ and $30.0 \%$ respectively and male and female ratio in their study was $1.67: 1$, which is consistent with our result.

In Group A $62.5 \%$ were smoker and in Group B $50.0 \%$. In group A and group B 7.5\% from each group had history of taking alcohol. Diabetes mellitus present in $42.5 \%$ and $27.5 \%$ in Group A and Group B respectively. In group A $55.0 \%$ had HTN and in group B 40.0\% had Hypertension. Atrial fibrillation, Aortic stenosis and stroke observed in both group A and group B and were $45.0 \%$ and $60.0 \%, 15.0 \%$ and $7.5 \%$ and $5.0 \%$ and $5.0 \%$ respectively. In the present study there is no statistically significant difference in age, sex, occupation, smoking habit and medical condition between the groups. In Mutiranrura et al. ${ }^{11}$ series $48.4 \%$ of early acute group and $56.7 \%$ of late acute group were smoker and $27.5 \%$ patients were hypertensive and $27.5 \%$ were diabetic.

Acute ischemic pain (93.4\%) was the most common clinical manifestation of acute arterial embolism of their series followed by pallor $(94.5 \%)$, sensory loss $(86.8 \%)$, and paralysis (74.7\%). Muscle weakness was more 
predominant in late acute embolism (86.7\% vs. $51.6 \%, \mathrm{p}<0.001)$. In our series pain and absence of pulse distal to occlusion were the common clinical presentation. More than ninety percent (92.5\%) patients of Group A and nearly all cases in Group B (97.5\%) had cold extremity. Only $12.5 \%$ and $7.5 \%$ patients in Group A and Group $\mathrm{B}$ had intact sensory function respectively. In Group A and Group B had intact motor function $20.0 \%$ and $10.0 \%$ respectively. By Doppler USG evaluation only $2.5 \%$ patients of Group A had found diminish vascular flow and rests $97.5 \%$ had absent vascular flow and in Group B 5.0\% and $95.0 \%$ patients had diminished and absent vascular flow respectively.

In Group A 57.5\% had superficial femoral artery occlusion followed by $22.5 \%$ iliac artery and $20.0 \%$ popliteal artery occlusion. In Group B $42.5 \%$ had superficial femoral artery occlusion, $32.5 \%$ had popliteal artery occlusion and $25.0 \%$ had iliac artery occlusion. Antusevas and Aleksynas, ${ }^{10}$ in a study showed that thrombosis damaged the femoral artery for $37.9 \%$, iliac artery for $22.7 \%$, popliteal artery for $22.2 \%$ patients and embolism was in the femoral artery for $32.9 \%$, popliteal artery for $4.7 \%$, and tibialis artery for $7 \%$ patients.

In Group A, 27.5\% had viable muscle, $67.5 \%$ had borderline and $5.0 \%$ had no viability and in Group B $22.5 \%$ had viable muscle, $67.5 \%$ had borderline and $10.0 \%$ had dead muscle ( $p>0.05$ ). Fasciotomy was performed in $15.0 \%$ patients of Group A and $22.0 \%$ patients of Group B $(p>0.05)$. After Fogarty embolectomy $80.0 \%$ patient of Group A and $65.0 \%$ of Group B had warm extremity and 90.0\% and $75.0 \%$ patients in Group A and Group $\mathrm{B}$ had pulsation distal to occlusion respectively. In Group A and Group B, 82.5\% and 67.5\% patients had intact sensory function and $80.0 \%$ and $65.0 \%$ had intact motor function. Doppler US evaluates $80.0 \%$ patients of Group A and $65.0 \%$ patients of group B had normal vascular flow. No statistically significant differences were observed between groups in term of different outcomes. During postoperative period $12.5 \%$ patients of Group A and 10.0\% of Group B had history of bleeding, $5.0 \%$ of Group A and $7.5 \%$ of Group B had developed infection, 17.5\% patients of Group A and 35.0\% patients of Group B had reperfusion injury. Muscle necrosis and limb amputation was observed in $15.0 \%$ and $12.5 \%$ patients of Group A and $37.5 \%$ and $32.5 \%$ patients of Group B respectively $(p<0.05)$. Similar observation was seen in Mutiranrura et al. ${ }^{11}$ series. Limb ischemia beyond 24 hours of their series had the tendency to result in extensive gangrene $(3.2 \%$ vs. $26.7 \%, \mathrm{p}<0.015)$ and a higher incidence of primary major amputation $(3.2 \%$ vs. $20.0 \%$, p < 0.05$)$. Antusevas and Aleksynas, ${ }^{10}$ in a study showed the total death rate in the group of 142 patients with acute leg ischemia was $4.2 \%$ (6 patients), the death rate in the of 76 patients with emboli group was $5.3 \%$ (4 patients) and in the of 66 patients with acute thrombosis group - 3\% (2 patients). Iyem and Eren, ${ }^{12}$ in a study showed that complications like fasciotomy, amputation; Infection, Myonephropathic metabolic syndrome; venous thrombosis and mortality were $11.47,7.37,9.01,4.09,2.45$ and 9.01. Abir et al. ${ }^{13}$ and Cranley et al. ${ }^{14}$ in their study showed that amputation rate following operations undertaken during the first 12 hours is reported in the range of $2.1 \%$ to $5.9 \%$; but the rate increases to $39.2 \%$ after 12 hours. Hight et al. ${ }^{15}$ analyzed 11 different series between 1954 and 1974 and determined an amputation rate of $4 \%$ to $48 \%$ and a mortality rate of $14 \%$ to $50 \%$. In a study by Yangni et al. ${ }^{16}$ that included 24 patients, the amputation rate was reported as $29.2 \%$ and the mortality rate as $29.2 \%$. In another study by Karapolat et al. ${ }^{17}$ the amputation rate of arterial embolectomy beyond 24 hours was reported to be $11.4 \%$. Iyem and Eren, ${ }^{12}$ in a study showed that $11.47 \%$ had fasciotomy and $7.37 \%$ had amputation. Becquemin and Kovarsky, ${ }^{18}$ and Pellegrino, ${ }^{19}$ in their study found that the major amputation rate in thrombosis and embolism cases were $16.0 \%$ and $11.0 \%$. Illuminati et al. ${ }^{20}$ in their study found that the major amputation rate in thrombosis and embolism cases were $37.7 \%$ and $17.2 \%$ and Kuukasjarvi and Salenius, ${ }^{21}$ in their study found that the major amputation rate in thrombosis and embolism cases were $26.0 \%$ and $10.0 \%$.

Due to the toxic metabolic product accumulated in and released by the more than 24-hour ischemic tissue, alteration of the systemic haemodynamics leading to multiple organ dysfunction and major amputation was not uncommon of major limb loss before and after revascularization and the less successful outcomes of treatments were observed in those patients with more than 24 -hour duration. 
Complete revascularization rate was observed in both group of our study was $80.0 \%$ and $65.0 \%$ respectively $(p>0.05)$. The successful revascularization after the initial embolectomy was similar in Mutiranrura et al. ${ }^{11}$ series in the management of early acute embolism than that of late acute embolism $(83.9 \%$ vs. $58.3 \%$, p < 0.001$)$. These were the consequence of the adhesiveness between the emboli and the endothelium of the occluded arterial segment where the duration occlusion lasted more than 24 hours. Therefore, the complete removal of those emboli could not be simply accomplished by surgical embolectomy alone. Despite the deployment of varying modalities of primary treatment, major amputation after revascularization in patients with late acute embolism superseded those with early acute embolism $(24.4 \%$ vs. $7.4 \%$, p < 0.106$)$. Total death rate was reported $5.0 \%$ and $10.0 \%$ for Group A and Group B respectively. Almost similar result ( $9.7 \%$ vs. $15.0 \%)$ was observed by Mutiranrura et al. ${ }^{11}$. Taviloglu et al. ${ }^{22}$ showed that mortality rates have reported as $12.5 \%$ within 12 hours and $37.7 \%$ thereafter.

\section{Conclusion:}

Duration of embolism may be the significant factor determining the outcomes of the management of acute arterial embolism in the lower extremities. The higher tendency of developing extensive limb gangrene, the higher number of major limb loss before and after revascularization and the less successful outcomes of treatments were observed in those patients with more than 24-hour duration.

\section{Recommendation:}

Duration of arterial embolism is a crucial factor influencing the surgical management of acute lower limb ischaemia due to thromboembolism. So, early diagnosis and shifting of patients to specified centre as early as possible to save limb as well as life.

\section{Conflict of Interest - None.}

\section{References:}

1. Eliason JL, Wainess RM, Proctor MC et al. A National and Single Institutional Experience in the Contemporary Treatment of Acute Lower Extremity Ischemia. Ann Surg 2003 September; 238(3): 382-390.

2. Lenti M, Costantini V. Treatment of acute occlusion of peripheral arteries. Thromb Res 106:295-294.

3. Andersson B, Abdon NJ, Hammarsten J. Arterial embolism and atrial arrhythmias. Eur J Vascular Surg 1989;3: 261-266.
4. Kuukasjarvi P, Riekkinen H, Salenius JP, Vattulainen K, Lindholm S. Prevalence and predictive value of ECG findings in acute extremity ischemia. J Cardiovasc Surg (Torino) 1995;36:469-473.

5. Keeley EC and Hillis LD. Left ventricular mural thrombus after acute myocardial infarction. Clin Cardiol 1996;19:8386.

6. Kitts D, Bongard FS, Klein SR. Septic embolism complicating infective endocarditis. J Vasc Surg 1991;14:480-485.

7. Dormandy J, Heek L, Vig S. Acute limb ischemia. Semin Vasc Surg 1999; 12:148-153.

8. Davies B, Braithwaite BD, Birch PA, Porskitt KR, Heather BP, Earnshaw JJ. Acute leg ischaemia in Gloucestershire. Brit J Surg 1997;84:504-508.

9. Bergquist D, Troeng T, Elfstrom J, Hedberg B, Ljungstrom KG, Norgrem L. Auditing surgical outcome: ten years with the Swedish Vascular Registry Swedvasc. The Steering Committee of Swedvasc. Eur J Vasc Endovasc 1998;164:3-8.

10. Antusevas A and Aleksynas N. The surgical treatment of the lower limb acute ischemia. Medicina 2003;39(7):646653.

11. Mutirangura P, Ruangsetakit C, Wongwanit C, Sermsathanasawadi N, Chinsakchai K. Acute Arterial Embolism of the Lower Extremities: Impact of 24-Hour Duration on the Outcome of Management. J Med Assoc Thai 2008;91 (9):1360-1367.

12. Iyem and Eren MN. Should embolectomy be performed in late acute lower extremity arterial occlusions? Vasc Health Risk Manag 2009; 5: 621-626.

13. Abir F, Barkhordorian B, Sumpio BE. Non cardiac vascular complications of coronary bypass procedures: A review. Int $J$ Angiol 2004;13:1-6.

14. Cranley JJ, Krause RJ, Strasser ES, Hafner CD, Fogarty TJ. Peripheral arterial embolism: Changing concepts. Surgery 1964;55:57-63.

15. Hight DW, Tilney NL, Couch NP. Changing clinical trends with arterial emboli. Surgery. 1976;79:172-176.

16. Yangni AH, Adoubi A, Adoh M, Yapobi Y, Coulibaly AO. Acute nontraumatic limb ischemia. West Afr $J$ Med 2006;25:101-104.

17. Karapolat S, Dag O, Abanoz M, Aslan M. Arterial embolectomy: a retrospective evaluation of 730 cases over 20 years. Surg Today 2006;36:416-419.

18. Becquemin JP and Kovarsky S. Arterial emboli of the lower limbs: analysis of risk factors for mortality and amputation. Association Universitaire de Recherche en Chirurgie. Riv Eur Sci Med Farmacol 1996;18(1):19-27.

19. Pellegrino F. Acute ischemia of the extremities caused by thromboembolism. Eur J Vascular Surg 1987;1(4):263-271.

20. Illuminati G, Bertagni A, Calio FG et al. Acute ischemia of the lower limbs. Br J Surg 1993;80(5):592-595.

21. Kuukasjarvi P, Salenius JP. Perioperative outcome of acute lower limb ischaemia on the basis of the national vascular registry. The Finnvasc Study Group. Am Surg 1997;63(3):270-274.

22. Taviloglu K, Gunay K, Asaoglu O, Guloglu R, Kurtoglu M. Is primary amputation required in peripheral arterial occlusion cases that are admitted to the clinic with 12hour delay? Turkish J Vasc Surg 1995;4:91-96. 